\title{
INVESTIGATION OF THREE-DIMENSIONAL DYNAMIC DELAMINATION IN CURVED UNIDIRECTIONAL CFRP LAMINATES
}

\author{
Tamer T. Ata ${ }^{1,2}$, Demirkan Coker ${ }^{2,3^{*}}$ \\ ${ }^{1}$ Dept. of Aerospace Engineering, METU, Ankara, Turkey \\ ${ }^{2}$ Helicopter Group, Turkish Aerospace Industries (TAI), Ankara, Turkey \\ ${ }^{3}$ RÜZGEM (METUWIND) Center for Wind Energy Research, METU, Ankara, Turkey \\ *coker@metu.edu.tr
}

In this study, dynamic delamination of unidirectional curved CFRP laminates is investigated using 3D finite elements in explicit analysis. Cohesive elements are utilized to simulate both delamination initiation and propagation. Also, general contact interaction is assigned to prevent penetration of adjacent layers under large displacements. The simulations are based on the experiments of Tasdemir [1]. Delamination initiation is observed to occur exactly at the center of the specimen along the width direction and then propagate to the edges and arms (Figure 1a). Crack tip speed as a function of the crack extension from the center of the curved region for 3D crack tip at the center and the free edge are shown in Figure 1(b), both reaching intersonic crack tip speeds. 3D finite element analyses of dynamic delamination in curved unidirectional CFRP laminates revealed that the crack propagation speeds inside the laminate vary as edge crack travels faster than the center crack. The evolution of the contact region is behind the delamination front is discussed.
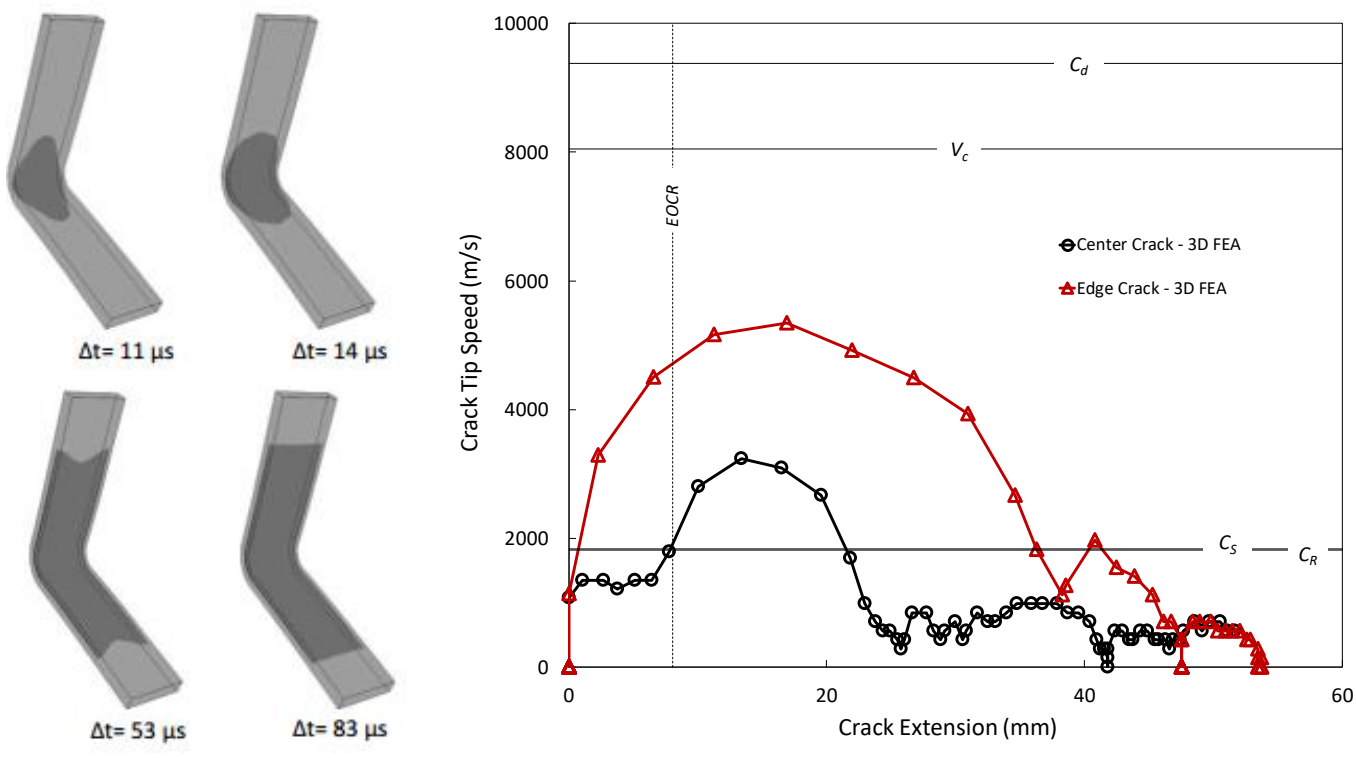

Figure 1. (a) Delamination propagation in 3D FEA, (b) Crack tip speed as a function of the crack extension from the center of the curved region for 3D crack tip at the center and the edge.

\section{References}

[1] B. Tasdemir (2018) Fatigue and Static Behavior of Curved Composite Laminates. MSc Thesis, Middle East Tech Univ. 